\title{
Study about Nature of Science in Undergraduate Research Training
}

\author{
Mazen Alrahili \\ Department of Physics \\ Clark Atlanta University, Atlanta, GA, 30313, USA
}

\begin{abstract}
Undergrad research can bolster understudies' more focal investment in material science. We dissect markers of two coupled moves in interest: changes in understudies' perspectives about the way of science coupled with moves in self-viability toward material science investigate. Understudies in the study worked with personnel and graduate understudy coaches on research ventures while likewise taking an interest in a workshop where they found out about look into and thought about their encounters. In classroom talks and clinical meetings, understudies portrayed increasing more nuanced perspectives about the way of science, particularly identified with who can take an interest in research and what support in research resembles. This move was coupled to picks up in self-efficacy toward their capacity to add to research; they felt like their commitments as fledglings mattered. We show two contextual analyses of understudies who experienced coupled moves in selfadequacy and perspectives about nature-of-science movements, and a contextual investigation of an understudy for whom we didn't see either move, to represent both the presence of the coupling and the diverse ways it can play out. After presenting the defense that this coupling happens, we talk about some potential basic components. At long last, we utilize these outcomes to contend for additional nuanced translations of self-adequacy estimations.
\end{abstract}

\section{General Terms}

Undergraduate Training and Experience

\section{Keywords}

Undergraduate Training. Nature of Science

\section{INTRODUCTION}

Taking an interest in research is an essential part of turning into a physicist. Undergrad research can offer assistance encourage understudies' move from considering themselves to be material science understudies to considering themselves to be more focal members in the material science group [1]. Examine encounters can likewise expand understudies' steadiness in science, innovation, building and arithmetic (STEM) [2]. Earlier learns about undergrad look into illuminate a wide arrangement of national proposals to increment the quantity of college understudies taking part in material science inquire about [2,3]. Those studies recommend that undergrad inquire about benefits understudy from various perspectives, including the improvement of specialized aptitudes, content learning, and understudies' character and convictions about doing science [4-6]. Undergrad examine encounters likewise affect profession decisions, clearing up understudies' enthusiasm for seeking after graduate contemplates $[4,5]$. These outcomes are steady over a scope of STEM disciplines and distinctive research strategies, including understudy studies [5-7] and ethnographic examinations $[4,8,9]$. For example, a subjective study by Laursen et al. distinguishes understudy depicted and workforce portrayed advantages of doing research in effective summer undergrad investigate programs $[4,8,9]$. They found that the most habitually

communicated benefits incorporate figuring out how to take on a similar mindset as a researcher (counting information of logical substance and procedures) what's more, individual expert increases, which incorporates a feeling of individual having a place and convictions about one's capacity to do science [4]. Taraban and Logue, utilizing the Undergraduate Inquire about Questionnaire (URQ) [5,10], achieved comparative conclusions. They observed that understudies enhanced the most in research attitude, which tests self-idea and selfefficacy, and in addition examine strategies, which tests selfefficacy about doing test look into. So also, Lopatto made a Survey of Undergraduate Research (Beyond any doubt) and found the most noteworthy picks up in understudies' selfreported finding out about how the examination procedure functions furthermore, planning for future research [6]. Be that as it may, undergrad research is not similarly profitable for all understudies. The degree to which understudies advantage relies on upon the sort of research program, the everyday work (e.g., "genuine" work versus scut work), and mentorship quality [5,11,12]; guides who invest more energy with the mentee and make themselves more accessible have a tendency to be connected with more positive personality advancement and learning picks up $[5,9,11,12]$. In rundown, past examinations of undergrad research encounters have archived.

(1) Self-efficacy and learning about the doing of science as two noteworthy ranges in which understudies appear positive movements.

(2) Coarse-grained components, for example, tutor time duty furthermore, the scholarly wealth of understudies' everyday exercises, that add to these and other positive movements.

\section{STUDY SELF-EFFICACY}

The coupling between self-viability and perspectives about the nature of science merits concentrate somewhat because, taken independently, the two builds are significant in their possess right. Undergrad explores encounters can likewise prompt to positive moves in both, as talked about above. In this area, we facilitate contend for the significance of these two develops, illuminate what we mean by them, and pinpoint which parts of the develops, we will focus on our investigation. 


\subsection{Self-Efficacy}

Self-viability, faith in one's capacity, is attached to understudy accomplishment in material science [13], the determination in school [14,15], and intrigue [15]. In any case, extraordinary studies have operationalized this develop in various ways. Bandura at first characterized self-viability as convictions in one's capacity to finish a particular undertaking, and this build was installed in a bigger social subjective hypothesis of epistemic office and learning [16]. Examine grounded in these thoughts frequently comprises of vast $\mathrm{N}$ thinks about affirming Bandura's theorized patrons to self-viability: dominance encounters (succeeding at undertaking), vicarious encounters (e.g., seeing somebody "like you" prevail at an undertaking), verbal influence (getting consolation or disheartening from others), Furthermore, physiological components (deciphering physical and enthusiastic reactions, for example, tension) [16,17]. As adjusted to investigations of arithmetic and science learning, self-adequacy is typically more extensive than faith in capacity to finish a particular errand. For instance, the Sources of Self-Efficacy in Science Courses-Physics (SOSESC-P) [18] review requests understudies' level of (dis)agreement with proclamations, for example,

"I am fit for accepting decent evaluations on my assignments in this class."

"Listening to the teacher and different understudies in question-and-answer sessions makes me feel that I can't comprehend material science."

"I don't for the most part stress over my capacity to fathom material science issues." [19]

These things test understudies' self-viability for succeeding in their material science class. By differentiation, different scientists have made subscales focusing on self-viability about research. For case, one subscale on the URQ [10], Research Techniques, particularly tests self-adequacy for research, with these six things:

"I can configuration tests."

"I investigate tests."

"I see how to report test comes about."

"Producing speculations is something I can do."

"Information investigation is something I can do."

"Doing analyses is something I can do."

Take note of that the initial five things adjust to Bandura's unique idea of self-viability as connected with a particular errand.

In any case, in reporting comes about, numerous material science training specialists regularly concentrate on the subscale as entire, translating it as self-viability about research when all is said in done. What rose in our information was a more extensive feeling of certainty than the kind examined by individual things in the URQ Research Methods subscale; understudies came to trust that they could make significant commitments to bona fide investigate, without fundamentally determining particular research undertakings. In this paper, we name understudy proclamations identified with certainty and capacity in research as self-adequacy for research, or just self-viability for a short while recognizing that we are utilizing this term more comprehensively than a few.

\subsection{A glance about Nature of Science (NOS)}

Numerous science teachers, including the individuals who contemplate undergrad look into encounters, consider complex sees about the way of science to be an instructional objective in its own privilege [8,20-22]. In this area, we spell out which parts of understudies' perspectives about the way of science (NOS) are investigated underneath, relating those perspectives to past writing on understudies' NOS sees. To set up this talk, we first quickly audit how sees about the nature of science have typically been operationalized and concentrated on in instructive settings. NOS sees, as concentrated on in the vast majority of the science instruction writing, are convictions about "the epistemology of science, science as a method for knowing, or the qualities and convictions natural to logical information and its advancement,"

e.g., convictions about the nature and era of logical information [20]. Lederman et al. [21] describe these perspectives as having a place with a few interrelated measurements: "logical information is (i) speculative; (ii) exact; (iii) hypothesis loaded; (iv) incompletely the item of human induction, creative ability, and imagination; and (v) socially and socially inserted." Lederman et al. [21] recognize that their NOS instruments, the Views about Nature of Science (VNOS) shapes A through C, accentuate parts of NOS which are most available to K-12 understudies. By difference, our information talk most straightforwardly to understudies' perspectives about how science is done-how logical learning is developed - - in cooperative scholarly research centers. This is a cut of the nature of science to which K-12 understudies have little get to also, which can fluctuate by (sub)discipline, explore aggregate, and examine objectives for a specific venture [23-25]. In this way, it makes sense that VNOS and comparative conventions or overviews don't "get at" the parts of NOS whereupon we center, as depicted underneath. Despite the fact that our study did not particularly focus on any specific parts of understudies' perspectives about the NOS, two angles rose as focal in understudies' depictions of their encounters:

(i) The appropriated way of logical work - understudies' sees about the degree to which various specialists, with various levels of ability, genuinely add to the era of logical information.

(ii) The interaction of hypothesis, reproduction, and exact work - understudies' perspectives about the degree to which hypothetical considering, recreations or displaying, and exact information accumulation and examination communicate in complex ways. Take note of that (i) and (ii) inhabit the convergence of the epistemology of science, tending to parts of how logical information is socially developed [26,27], and the humanism of study as examined by anthropologists, history specialists, what's more, sociologists (now and then under the flag "science thinks about") trying to comprehend the way of life and collaborations of researchers [24,25,28 30]. Likewise, (ii) alludes not to understudies' understanding that experimental information is focal to science (Lederman et al's. second measurement of NOS), be that as it may, to understudies' understandings of how experimental, recreation on the other hand displaying, and hypothetical work collaborate in nuanced, various routes in various logical examinations. 


\section{CONNECTING BETWEEN THE SHIFTS IN SELF-EFFICACY AND NOS VIEWS}

In this area, we depict a conceivable association between Frederick's development in self-viability and moves in his perspectives about the way of science. After some further class talk, he expounds on not feeling anxious any longer and recommends that not comprehending what one is doing is alright in research. I ought to likely detailed. What I implied, it's a handle. Anxious about the procedure. I strolled into something where I had no clue what I was doing, Logan [my partner] had no clue what he was doing, [my mentor] had no clue what he was doing. That was our coach and he resembled, I don't know where this is going to go. The way toward learning and comprehension our subject so rapidly gave me a great deal of certainty that I could walk

into any of them, and lift it up that way, the procedure would be a considerable measure easier, I wouldn't be anxious about it. One unequivocally expressed wellspring of Frederick's selfadequacy is getting his exploration rapidly, which is what Bandura would call a dominance encounter. We contend that another calculate Frederick's expansion in self-adequacy is that his guide "didn't recognize what they were doing." Specifically, since his guide had "no clue what he was doing," Frederick trusted that analysts who don't recognize what they are doing can partake in research. We recognize that the association between self-efficacy what's more, NOS perspectives is less watertight in Frederick's information than in Wyatt's. Not at all like Wyatt, Frederick does not unequivocally express this causal connection in his depiction. Nonetheless, his verbose spill out of examining apprehension to accentuating how "no one realizes what they're doing" recommends that his work day in NOS sees adds to his day of work in self-efficacy.

\section{THEORETICAL FRAMEWORK}

Social Cognitive Career Theory (SCCT) is a hypothetical system from the reach of vocation advising that lights up how learning encounters like undergrad research encounters (UREs) can affect profession aspirations (Brown and Lent, 1996; Lent, Brown, and Hackett, 1994, 2000). Accordingly, in our push to investigate connections amongst UREs and vocation results, SCCT gives a potential component to changes in profession interests. SCCT is an outgrowth of Social Cognitive Theory (Bandura, 1977) and positions its components of self-viability and result hopes as drivers of individual profession decision activities. Self-adequacy can be characterized as "the conviction that one can effectively execute the conduct required to deliver the results" (p. 193), though result hope is the desire that specific practices will create attractive results. In SCCT individuals' convictions about themselves are an intense determinate of vocation interest and accomplishment. On the off chance that the understudy does not trust she would be a competitor important to a doctoral level college, that low self-viability will drive the improvement of profession interests, objectives, and activities.

In the SCCT demonstrate (Figure 1), self-viability and result desires are affected by upstream patrons like individual information sources, foundation elements, and learning encounters. Individual foundation components like financial status and family desires may influence access to learning encounters. Logical ecological variables can be distal or proximal and can give affordances or boundaries. For instance, an individual information like race or sex may present points of interest or hindrances in a given social setting, for example, the nearness of generalizations or good examples.

To represent how SCCT parts may collaborate in the quest for research-situated science professions, consider a Latina original undergrad. Notwithstanding when she effectively finishes the required science significant courses, she might be probably not going to view herself as a possibility for a URE. Those individual and foundation variables may force a few boundaries in getting to learning encounters, distinguishing vocation models, creating self-viability and utilizing information.

Cocoa and Lent (1996) call attention to that understudy convictions about different professions might be defective and that, therefore, people may kill some vocation alternatives rashly. Specifically, understudies' view of the result anticipations connected with those professions could conceivably mirror the substances of those fields. While selfadequacy and vocation objective setting happen through individual thoughtfulness, SCCT portrays profession wisdom as a dynamic and social process, open to the impact of outside gatherings and new encounters. Subsequently, intercessions went for expanding self-viability, tending to obstructions connected with specific vocation ways, building up positive logical impacts, and giving data identified with understudies' result.

This model has beforehand been connected to study understudy intrigue and quest for STEM fields (e.g., Chakraverty and Tai, 2013; Soldner, Rowan-Kenyon, and Inkelas, 2012), particularly among understudies from gatherings generally underrepresented in the sciences (e.g., da Silva Cardoso, Dutta and Chiu, 2013; Deemer, Thoman, and Chase, 2014; Lent, Miller, and Smith, 2013) or generally vulnerable,as Loaned and his partners (2005) investigated the vocation premiums and objectives of understudies in basic designing courses at both overwhelmingly White and g Black universities, finding that

\section{DISCUSSIONS AND FUTURE WORK}

Past work on undergrad look into encounters, notwithstanding when depending on meetings instead of studies, by and large winds up coding and arranging reactions rather than recounting stories about individual understudies' encounters [8]. This study exhibits the estimation of rich depictions of understudies' self-adequacy and NOS sees in undergrad look into encounters. Earlier quantitative work focusing on the results of undergrad research encounters has been significant in showing that undergrad explore encounters prompt to a few positive results, incorporating shifts in self-adequacy and in NOS sees [4-12]. The field would now profit by fine-grained subjective and quantitative investigations of how the positive results come to fruition and the logical elements that have any kind of effect. Building up a subjective "vibe" for these movements in self-adequacy and NOS perspectives is particularly essential when considering settings, for example, the Physics 299B explore class, where the exploration ventures are variegated.

\section{ACKNOWLEDGEMENTS}

This research is funding by Saudi Arabian Cultural Mission (SACM) through Taibah University. This support is greatly appreciated. 


\section{REFERENCES}

[1] P. W. Irving and E. C. Sayre, Conditions for building a community of practice in an advanced physics laboratory, Phys. Rev. ST Phys. Educ. Res. 10, 010109 (2014).

[2] S. Olson and D. G. Riordan, Engage to Excel: Producing One Million Additional College Graduates with Degrees, in Science, Technology, Engineering, and Mathematics. Report to the President (Executive Office of the President, Washington, DC, 2012).

[3] Business-Higher Education Forum (BHEF), The U.S. STEM Undergraduate Model: Applying System Dynamics to Help Meet President Obamas Goals for One Million STEM Graduates and the U.S. Navys Civilian STEM Workforce Needs, Tech. Rep. (2013).

[4] E. Seymour, A.-B. Hunter, S. L. Laursen, and T. DeAntoni, Establishing the benefits of research experiences for undergraduates in the sciences: First findings from a three-year study, Sci. Educ. 88, 493 (2004).

[5] R. Taraban and E. Logue, Academic factors that affect undergraduate research experiences J. Educ. Psychol. 104, 499 (2012).

[6] D. Lopatto, Survey of Undergraduate Research Experiences (SURE): First findings, Cell Biol. Educ. 3, 270 (2004).

[7] R. E. Landrum and L. R. Nelsen, The undergraduate research assistantship: An analysis of the benefits, Teach. Psychol. 29, 15 (2002).

[8] A.-B. Hunter, S. L. Laursen, and E. Seymour, Becoming a scientist: The role of undergraduate research in students' cognitive, personal, and professional development, Sci. Educ. 91, 36 (2007).

[9] S. Laursen, A.-B. Hunter, E. Seymour, H. Thiry, and G. Melton, Undergraduate Research in the Sciences: Engaging Students in Real Science (John Wiley \& Sons, New York, 2010).

[10] R. Taraban and R. L. Blanton, Creating Effective Undergraduate Research Programs In Science: The Transformation from Student to Scientist (Teachers College Press, New York, NY, 2008).

[11] S. E. Branch, A. Woodcock, and W. G. Graziano, Person orientation and encouragement: Predicting interest in engineering research, J. Eng. Educ. 104, 119 (2015).

[12] D. Lopatto and S. Tobias, Science in Solution: The Impact of Undergraduate Research on Student Learning (Research Corporation for Science Advancement, Tucson, AZ 2009), 1st ed.

[13] V. Sawtelle, E. Brewer, and L. H. Kramer Exploring the relationship between self-efficacy and retention in introductory physics, J. Res. Sci. Teach. 49, 1096 (2012).

[14] M. Bong, Role of self-efficacy and task-value in predicting college students' course performance and future enrollment intentions, Contemp. Educ. Psychol. 26, 553 (2001).
[15] K. D. Multon, S. D. Brown, and R. W. Lent, Relation of self-efficacy beliefs to academic outcomes: A metaanalytic investigation., J. Counsel. Psychol. 38, 30 (1991).

[16] A. Bandura, Self-Efficacy: The Exercise of Control (Freeman, New York, 1997).

[17] S. L. Britner and F. Pajares, Sources of science selfefficacy beliefs of middle school students, J. Res. Sci. Teach. 43, 485 (2006).

[18] H. Fencl and K. Scheel, Engaging students: And examination of the effects of teaching strategies on selfefficacy and course climate in a nonmajors physics course, J. Coll. Sci. Teach. 35, 20 (2005).

[19] V. Sawtelle, Ph.D. thesis, Florida International University, 2011.

[20] N. G. Lederman, Students' and teachers' conceptions of the nature of science: A review of the research, J. Res. Sci. Teach. 29, 331 (1992). [21] N. G. Lederman, F. Abd-El-Khalick, R. L. Bell, and R. S. Schwartz, Views of nature of science questionnaire: Toward valid and meaningful assessment of learners' conceptions of nature of science, J. Res. Sci. Teach. 39, 497 (2002).

[21] A. Elby, C. Macrander, and D. Hammer, Epistemic cognition in science, Handbook Epistemic Cognition (Routledge, New York, NY, 2016). CONNECTING SELF-EFFICACY AND VIEWS ... PHYS. REV. PHYS. EDUC. RES. 12, 020140 (2016) 020140-13

[22] K. Dunbar, How scientists really reason: Scientific reasoning in real-world laboratories, Nature of Insight (The MIT Press, Cambridge, MA, 1995).

[23] K. K. Cetina, Laboratory studies: The cultural approach to the study of science, Handbook of Science and Technology Studies (Los Angeles, CA, 1995).

[24] B. Latour, Science in Action: How to Follow Scientists and Engineers through Society (Harvard University Press, Cambridge, MA, 1987).

[25] G. J. Kelly and J. Green, The social nature of knowing: Toward a sociocultural perspective on conceptual change and knowledge construction, Perspectives on Conceptual Change: Multiple Ways to Understand Knowing and Learning in a Complex World (Routledge, Mahwah, NJ, 1998). [27] D. Papineau, Philosophy of Science (Wiley Online Library, 1996).

[26] B. Latour and S. Woolgar, Laboratory Life: The Construction of Scientific Facts (Princeton University Press, Princeton, NJ, 2013).

[27] S. Shapin, Here and everywhere: Sociology of scientific knowledge, Annu. Rev. Sociol. 21, 289 (1995).

[28] M. Zenzen and S. Restivo, The mysterious morphology of immiscible liquids: A study of scientific practice, Social science information / International Social Science Council 21, 447 (1982). 
Communications on Applied Electronics (CAE) - ISSN : 2394-4714

Foundation of Computer Science FCS, New York, USA

Volume 6-No.4, December 2016 - www.caeaccess.org

\section{APPENDIX}

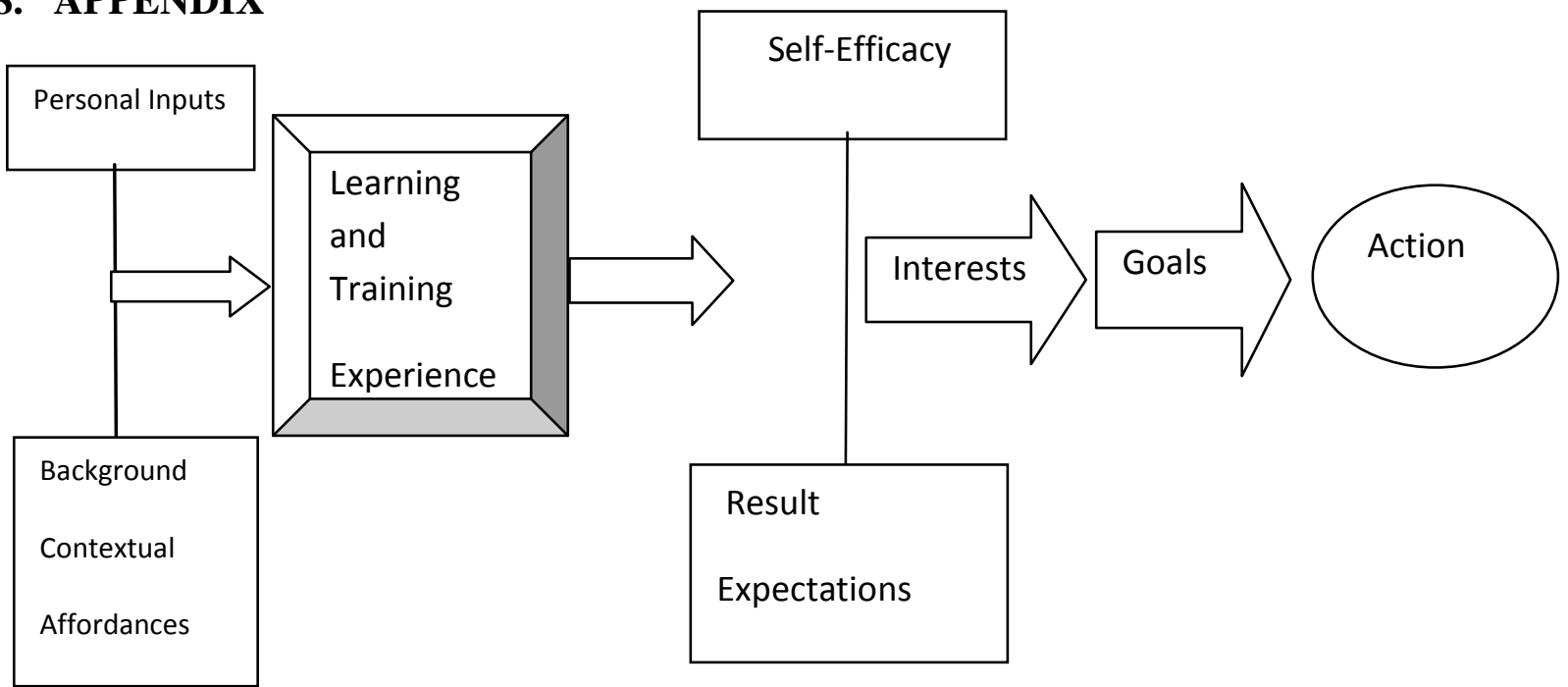

Figure 1. Model of Social Cognitive Influences on Career Behavior 